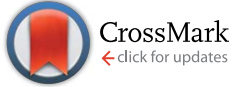

Cite this: RSC Adv., 2016, 6, 37995

Received 27th January 2016

Accepted 6th April 2016

DOI: $10.1039 / \mathrm{c} 6 \mathrm{ra02444k}$

www.rsc.org/advances

\title{
Cerium-doped gehlenite supporting silver/silver chloride for continuous photocatalysis $\uparrow$
}

\author{
Haoyi Wu, Wenqin Peng, Zheng-Ming Wang* and Kazuhide Koike
}

Herein a series of cerium-doped gehlenite supporting silver/silver chloride $\left(\mathrm{Ca}_{2} \mathrm{Al}_{2} \mathrm{SiO}_{7}: \mathrm{Ce}^{3+}-\mathrm{Ag} / \mathrm{AgCl}\right)$ composites are successfully fabricated and their phase structure, surface property, morphology and optical properties are examined. The $\mathrm{Ca}_{2} \mathrm{Al}_{2} \mathrm{SiO}_{7}: \mathrm{Ce}^{3+}$ shows a strong emission at $410 \mathrm{~nm}$ and a long-lasting afterglow is observed additionally. The emission and afterglow intensities are weakened by the decoration of $\mathrm{Ag} / \mathrm{AgCl}$ particles, which is caused by photoemission quenching and, partially, the internal filtering effect due to the decorated species. Such $\mathrm{Ca}_{2} \mathrm{Al}_{2} \mathrm{SiO}_{7}: \mathrm{Ce}^{3+}-\mathrm{Ag} / \mathrm{AgCl}$ composites can efficiently degrade methyl orange under solar irradiation, and this degradation proceeds continuously after the elimination of the external irradiation because of the long-lasting luminescence of the phosphor. Around 15\% of methyl orange can be degraded after light-off. Moreover, it was found that $\mathrm{Ag} / \mathrm{AgCl}$ is more suitable to compose with $\mathrm{Ca}_{2} \mathrm{Al}_{2} \mathrm{SiO}_{7}: \mathrm{Ce}^{3+}$ as compared to $\mathrm{TiO}_{2}$ because of its wide absorption window.

\section{Introduction}

The employment of semiconductors to degrade organic pollutants has been investigated extensively since the discovery of photocatalytic $\mathrm{TiO}_{2}$ in $1972 .{ }^{1-5}$ It is well known that such semiconductors can generate electrons and holes in the conduction band (CB) and valence band (VB), respectively, when they are excited by photo energy beyond their band gap energy. Parts of the electrons and holes which do not undergo charge annihilation can migrate to the surface of the semiconductor, which react with oxygen or water to form superoxide or hydroxyl radicals and then oxidize and decompose the absorbed molecules. ${ }^{6,7}$ The photocatalytic method is an environment-benign process for water purification, particularly, in outdoor environment where naturally available and inexhaustible solar is expected as the excitation source. For the purposes of such applications, the photocatalysts with wide spectrum light activity, the light-harvesting materials, and/or their composing materials are required to match the sunlight spectrum which ranges from ultraviolet to near infrared irradiations (containing less than $6 \%$ UV light $(<400 \mathrm{~nm})$ and $40-50 \%$ visible light $(400-850 \mathrm{~nm})$ besides the weak infrared light) and to utilize solar energy as utmost as possible. In term of the wide spectrum light-active photocatalysts, visible light-active photocatalysts such as the non-metal doped- $\mathrm{TiO}_{2}$, the metal deposited- $\mathrm{TiO}_{2}$, the dye-sensitized photocatalysts, the

Environmental Management Research Institute, National Institute of Advanced Industrial Science and Technology, Tsukuba 305-8569, Ibaraki, Japan. E-mail: zm-wang@aist.go.jp

$\dagger$ Electronic supplementary information (ESI) available. See DOI: $10.1039 / \mathrm{c} 6 \mathrm{ra} 02444 \mathrm{k}$ coupled semiconductors have been attempted to replace the typical photocatalytic semiconductors, ${ }^{8-10}$ e.g., $\mathrm{TiO}_{2}, \mathrm{ZnO}$, and $\mathrm{SrTiO}_{3}$, which can only be activated under UV (usually $<400 \mathrm{~nm}$ ) illumination. ${ }^{11-15}$ In recent years, a group of plasmonic photocatalysts have attracted a great deal of concern because of the synthesizing facility and the high visible light efficiency, ${ }^{\mathbf{1 6 , 1 7}}$ among which silver and silver chloride nanocrystal is the typical research subject with good photocatalytic performance. ${ }^{\mathbf{1 8 , 1 9}}$

Since solar light is usually subjected to the conditions of weather, it is expected that light storing materials are employed to compose with photocatalysts and act as the light supplier at the period of time when the external light source is unavailable. In such a way, changeable weather (cloudy and rainy days or even during the night) can be catered to minimize the influence of unstable irradiation. ${ }^{20-31}$ As the typical light storing materials, long-lasting phosphors (LLPs) can absorb and store light energy and release the energy as the form of photo-emission after the extinguishing of photoexcitation, enabling the luminescence to persist from several minutes to hours. ${ }^{32-35}$ There were some previous investigations which applied LLPs to support photocatalysts for decomposition of harmful pollutants. For example, Zhang et al. used a $\mathrm{Sr}_{4} \mathrm{Al}_{14} \mathrm{O}_{25}$ : Eu, Nd LLP layer as the bottom substrate of a $\mathrm{TiO}_{2}$ layer for decomposition of $\mathrm{RhB}$, which achieved $\sim 50 \%$ degradation in dark after repeating excitation of the LLP layer. ${ }^{20}$ Li et al. employed $\mathrm{Sr}_{4} \mathrm{Al}_{14} \mathrm{O}_{25}$ :Eu, Dy LLP particles to support $\mathrm{Ag}_{3} \mathrm{PO}_{4}$ particles by which a considerable amount of RhB was degraded..$^{21} \mathrm{Ma}$ et al. observed $10 \%$ degradation of methyl blue by $\mathrm{BaZrO}_{3}: \mathrm{Mg}$ loaded $\mathrm{TiO}_{2}$ after the switching-off of illumination. ${ }^{27}$ So far aluminate-based LLPs were frequently used for such purposes, which can emit at high brightness and with a long afterglow lifetime on one hand but 
are unstable and easily deteriorated in water or under moisture conditions on the other hand. The incompatible properties hinder their applications in water environment.

In order to achieve LLPs with stronger water resistivity, herein silicate-based cerium incorporated gehlenite LLP $\left(\mathrm{Ca}_{2}-\right.$ $\mathrm{Al}_{2} \mathrm{SiO}_{7}: \mathrm{Ce}^{3+}$ ) were synthesized by sol-gel method and hybridized with visible light-active $\mathrm{Ag} / \mathrm{AgCl}$ nanocrystals. The detailed structures and photoluminescent properties of the hybrid materials and their ability to degrade organic pollutants in aqueous environment was examined. We observed effective decomposition of methyl orange (MO) in aqueous condition under simulated solar excitation and an evident long lasting degradation ( $\sim 15 \%$ of the retained MO) after switching off excitation for these hybrid materials.

\section{Experimental section}

\section{Material synthesis}

$\mathrm{Ca}_{2} \mathrm{Al}_{2} \mathrm{SiO}_{7}: \mathrm{Ce}^{3+}$ LLP. The $\mathrm{Ca}_{2} \mathrm{Al}_{2} \mathrm{SiO}_{7}: \mathrm{Ce}^{3+}$ LLP was synthesized by sol-gel method. $\mathrm{Ca}\left(\mathrm{NO}_{3}\right)_{2}$ (Wako, 98.5\%), $\mathrm{Al}\left(\mathrm{NO}_{3}\right)_{3}$ (Wako, 98\%), $\mathrm{Ce}\left(\mathrm{NO}_{3}\right)_{3}$ (Wako, 98\%) and tetraethylorthosilicate (TEOS, Wako, 95\%) were used as the raw materials. The $\mathrm{Ca}\left(\mathrm{NO}_{3}\right)_{2}(0.02 \mathrm{mmol}), \mathrm{Al}\left(\mathrm{NO}_{3}\right)_{3}(0.02 \mathrm{mmol})$ and $\mathrm{Ce}\left(\mathrm{NO}_{3}\right)_{3}$ $(0.0002 \mathrm{mmol})$ were first dissolved in $10 \mathrm{~mL}$ aqueous solution. The solution was kept stirring until it became transparent. Meanwhile, TEOS $(0.011 \mathrm{mmol})$ was dissolved in $5 \mathrm{~mL} \mathrm{EtOH}$. Then the later solution was added to the former one under stirring. The mixture was kept stirring for $30 \mathrm{~min}$ at room temperature, and then transferred to an oil bath at $373 \mathrm{~K}$. A transparent gel was obtained after the evaporation of solvent, after which the gel was dried at $373 \mathrm{~K}$ overnight. Finally, the product was sintered at $1273 \mathrm{~K}$ for 2 hours under a $95 \% \mathrm{~N}_{2}+5 \%$ $\mathrm{H}_{2}$ atmosphere. The $\mathrm{Ca}_{2} \mathrm{Al}_{2} \mathrm{SiO}_{7}: \mathrm{Ce}^{3+} \mathrm{LLP}$, denoted as $\mathrm{G}$, was obtained after cooling down to room temperature. The $\mathrm{G}$ sample can survive in water much better as compared to a commercial Al-based phosphor with high brightness as shown in ESI and Fig. S1-S3. $\dagger$

Ag/AgCl photocatalysts. The $\mathrm{Ag} / \mathrm{AgCl}$ particles have been synthesized in the reported literature either by the surface deposition of $\mathrm{Ag} / \mathrm{AgCl}$ nanostructures on the microcubic seeds of sodium chloride ${ }^{36}$ or by the primary growth of $\mathrm{AgCl}$ nanostructures from $\mathrm{Ag}^{+}$in solution, ${ }^{19}$ with the latter method producing smaller particle size. Here we synthesized $\mathrm{Ag} / \mathrm{AgCl}$ nanoparticles by a modified method of ref. 19, in which aqueous phase instead of organic phase was used as the solvent. In this synthesis, $\mathrm{AgNO}_{3}$ (Wako, 99.8\%) and $\mathrm{NaCl}$ (Wako, 99.5\%) were employed as the raw materials and polyvinylpyrrolidone (PVP) (Wako, K25) as the modifier. $57 \mathrm{mg}$ $\mathrm{AgNO}_{3}$ was first dissolved in $10 \mathrm{~mL}$ aqueous solution to which $54 \mathrm{mg}$ PVP was added and the mixture (solution A) was stirred continuously until it became transparent. Meanwhile, $45 \mathrm{mg}$ $\mathrm{NaCl}$ was dissolved in another $2 \mathrm{~mL}$ aqueous solution which was then slowly added to solution A, during which white precipitations appeared gradually. The mixed solution was kept stirring overnight. After centrifuging and drying, the $\mathrm{Ag} / \mathrm{AgCl}$ powder, denoted as A, was collected.
$\mathrm{Ca}_{2} \mathrm{Al}_{2} \mathrm{SiO}_{7}: \mathrm{Ce}^{3+}-\mathrm{Ag} / \mathrm{AgCl}$ composite. $x \mathrm{mg} \mathrm{Ca}_{2} \mathrm{Al}_{2} \mathrm{SiO}_{7}: \mathrm{Ce}^{3+}$ $(x=5,25,50$ and 100) was dispersed in $x \times 0.4 \mathrm{~mL}$ water to form a dispersion B. Meanwhile, $5 \mathrm{mg} \mathrm{Ag} / \mathrm{AgCl}$ powder was dispersed in $2 \mathrm{~mL}$ water to form dispersion $\mathrm{C}$. The dispersion $\mathrm{C}$ was then dropped into dispersion $\mathrm{B}$ under continuous stirring and the stirring was kept for 4 hours. After centrifuging and drying, the $\mathrm{Ca}_{2} \mathrm{Al}_{2} \mathrm{SiO}_{7}: \mathrm{Ce}^{3+}-\mathrm{Ag} / \mathrm{AgCl}$ composites with a phosphor to catalyst weight ratio of $1: 1,5: 1,10: 1$ and $20: 1$ were obtained, which were denoted as G1A1, G5A1, G10A1 and G20A1, respectively.

Besides the composite samples, the G sample was also physically mixed with the commercial Degussa P25 $\mathrm{TiO}_{2}$ powders at a weight ratio of $10: 1$ by grinding the two materials in agate mortar for 1 hour. The physical mixture, denoted as G10T1, was used as the control sample for comparison.

\section{Characterization}

$\mathrm{X}$-ray diffraction (XRD) patterns of the sample were determined by a Rigaku Smartlab diffractometer with $\mathrm{CuK} \alpha$ irradiation $(0.15406 \mathrm{~nm})$ at $30 \mathrm{~mA}$ and $40 \mathrm{kV}$. Elemental analysis of the samples was carried out by a Rigaku EDXL 300 type Cartesian geometry energy dispersive X-ray fluorescence (XRF) spectrometer. The X-ray photoelectron spectroscopy (XPS) of the sample was measured on an ULVAC-PHI 5000 Versa Probe type instrument with an $\mathrm{Al} \mathrm{K} \alpha$ irradiation $(15 \mathrm{kV}, 25 \mathrm{~W}$, beam diameter: $0.1 \mathrm{~mm}$ ) and a neutralizer using argon ions and electron beams.

Fourier transform infrared (FT-IR) spectra of the samples were obtained by a Perkin Elmer spectrum 100 Optica type spectrometer equipped with an attenuated total reflection (ATR) attachment which has an MKII Golden Gate TM single reflection system consisting of a diamond crystal $45^{\circ}$ top plate, a sapphire anvil, and an Optics Unit with ZnSe lenses. Morphologies of sample were observed by a Hitachi S-4300 type field emission scanning electron microscope (FE-SEM) at an electron acceleration voltage of $1 \mathrm{keV}$. Transmission electron microscopic (TEM) observation and Energy-dispersive X-ray spectrum (EDX) analysis were carried out on a Topcon EM-002B apparatus operated at $120 \mathrm{kV}$.

The diffuse reflectance spectra (DRS) and absorption spectra of the samples were recorded by a JASCO V-650 type UV-Vis spectrometer. The photoluminescence (PL) and afterglow spectra of the samples were studied using a Shimadzu RF-5301PC type fluorescence spectrometer and the decay curves were obtained by plotting the time-dependent afterglow intensity after excitations. Prior to the afterglow and decay measurement, all samples were excited by a $350 \mathrm{~nm}$ excitation for 1 minute. The quantum yield values were determined by a Hamamatsu C11347 type quantum yield spectrophotometer.

\section{Photocatalytic experiment}

The typical dye pollutant methyl orange (MO) was chosen as the target molecule for photodegradation and afterglow degradation tests. $5 \mathrm{mg} \mathrm{Ag} / \mathrm{AgCl}$ composed with different amount of LLPs was mixed with $100 \mathrm{~mL}$ of $\mathrm{MO}$ solution at an initial concentration $\left(C_{0}\right)$ of $1 \mathrm{mg} \mathrm{\textrm {L } ^ { - 1 }}$ in a glass beaker which was sonicated for $2 \mathrm{~min}$ and capped with a quartz cover. The glass 
beaker was then put under a simulated solar excitation light source (Xe lamp, $300 \mathrm{~W}$ ) with the liquid surface $13 \mathrm{~cm}$ apart from the light source to assure an illuminance of $0.15 \mathrm{~W} \mathrm{~cm}^{-2}$ on the top of the solution. The temperature of the reactor was controlled to be $297 \pm 2 \mathrm{~K}$ in a water bath during the reaction. After adsorption equilibrium in dark for $30 \mathrm{~min}$ (step D), the solution was illuminated for 5 min (step I), following which the excitation was cut off and the mixture was kept stirring in dark for another 20 minutes (step A). A little amount (1 mL) of solution at different intervals was sampled in each step and MO concentration was analyzed by a Shimadzu Prominence high performance liquid chromatography (HPLC) system which consists of two liquid pumps of Model LC-20AD, a DGU-20A3 type degasser, a SIL-20AC type auto sampler, a CTO-20AC type column oven, and a SPD-M20A diode array detector, which assures a $10 \mu \mathrm{g} \mathrm{L}^{-1}$ limit of quantification of $\mathrm{MO}$ with a relative standard deviation of $4 \%$.

\section{Results and discussion}

\section{Bulk and surface properties}

Fig. 1 shows the XRD patterns of the pure gehlenite $(G)$, the pure $\mathrm{Ag} / \mathrm{AgCl}(\mathrm{A})$, and the prepared composite samples. The patterns of the G (Fig. 1(a)) and A (Fig. 1(f)) samples were confirmed to be the tetragonal $\mathrm{Ca}_{2} \mathrm{Al}_{2} \mathrm{SiO}_{7}$ and cubic $\mathrm{AgCl}$ phases, respectively, according to the JCPDF database (card numbers 87-0970 and $31-1238$, respectively). A small peak at $2 \theta=30.07^{\circ}$ (annotated with $\bigcirc$ ) was observed for $\mathrm{G}$, which can be indexed to monoclinic $\mathrm{CaAl}_{2} \mathrm{O}_{4}$ structure, indicating the formation of a little amount of impurity during the sintering process. Both the gehlenite and $\mathrm{AgCl}$ phases appear in all composite samples, manifesting the successful decoration of $\mathrm{Ag} / \mathrm{AgCl}$ on $\mathrm{Ca}_{2} \mathrm{Al}_{2}$ $\mathrm{SiO}_{7}: \mathrm{Ce}^{3+}$ in the composite. With increasing the amount of $\mathrm{Ag} /$ $\mathrm{AgCl}$, the peak intensity of the corresponding $\mathrm{AgCl}$ structure becomes stronger as compared to the $\mathrm{Ca}_{2} \mathrm{Al}_{2} \mathrm{SiO}_{7}$ structure,

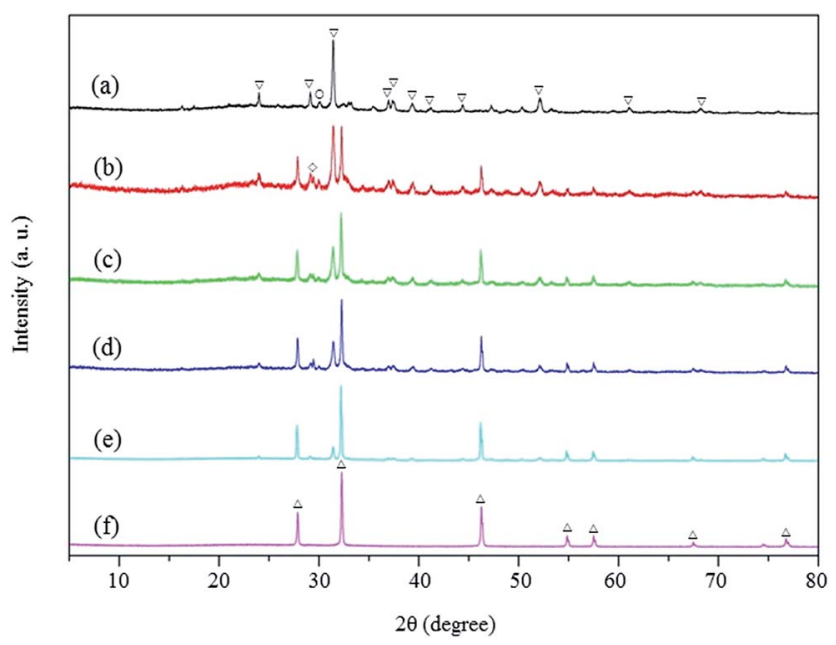

Fig. 1 XRD patterns of the $G$, the $A$, and the composite samples. (a) $G$, (b) G20A1, (c) G10A1, (d) G5A1, (e) G1A1, (f) A with $\nabla, \triangle, O$, and $\diamond$ indexing the gehlenite, the $\mathrm{AgCl}$, the $\mathrm{Ca}\left(\mathrm{AlO}_{2}\right)_{2}$, and the $\mathrm{Ca}_{2} \mathrm{CO}_{3}$ phases. characteristic of the gradual increase of decoration amount of $\mathrm{Ag} / \mathrm{AgCl}$ in the composite. In the meanwhile, a small peak at $2 \theta$ $=29.4^{\circ}$ (annotated with $\diamond$ ) (Fig. 1(b)-(e)) also appears in the composite samples, which can be indexed to the trigonal $\mathrm{CaCO}_{3}$ structure. This may be caused by the decomposition of $\mathrm{CaAl}_{2} \mathrm{O}_{4}$ which is present slightly in the sample as an impurity or the partial structural change of $\mathrm{Ca}_{2} \mathrm{Al}_{2} \mathrm{SiO}_{7}$ in water during the preparation process. Fig. 2 shows the weight ratio of $\mathrm{Ag}$ in the composite measured by the XRF method as a function of added stoichiometry of $\mathrm{Ag}$ in the preparation process. The linear relation indicates a good correlation between the added and the loaded amount of $\mathrm{Ag} / \mathrm{AgCl}$ on $\mathrm{G}$.

The XPS method was further applied to verify the elemental composition and their valence states in the G10A1 sample. As show in Fig. 3, the survey scan spectrum from 0 to $1000 \mathrm{eV}$ (Fig. 3(a)) displays the photoemission peaks from $\mathrm{Ca}, \mathrm{Al}, \mathrm{Si}, \mathrm{O}$, $\mathrm{Ag}$ and $\mathrm{Cl}$. The peaks locating at 367.8 and $373.7 \mathrm{eV}$ (Fig. 3(b)) are correspondent to the binding energy of $\mathrm{Ag} 3 \mathrm{~d}_{5 / 2}$ and $3 \mathrm{~d}_{3 / 2}$ respectively. These peaks can be deconvoluted into two components (367.4 and $368.3 \mathrm{eV}$, and 373.3 and $374.2 \mathrm{eV}$, respectively) ascribable to $\mathrm{Ag}^{+}$and $\mathrm{Ag}^{0}$ species, respectively. Thus, the $\mathrm{Ag} / \mathrm{AgCl}$ particles in the composite are of the mixed metallic $\mathrm{Ag}$ and $\mathrm{AgCl}$ properties. The molar ratio of $\mathrm{Ag}^{+}$to $\mathrm{Ag}^{0}$ in the composite is estimated to be $\sim 1.2$ from the peak intensity. The appearance of $\mathrm{Ag}^{0}$ is advantageous to the visible light absorption of $\mathrm{Ag} / \mathrm{AgCl}$ by the surface plasmon resonance (SPR). ${ }^{37}$ The peak at $199.1 \mathrm{eV}$ (Fig. 3(c)) can be split into two components at 198.1 and $199.6 \mathrm{eV}$, which correspond to the binding energy of $\mathrm{Cl} 2 \mathrm{p}_{3 / 2}$ and $2 \mathrm{p}_{1 / 2}$, respectively. In addition, a peak corresponding to the $3 \mathrm{~d}_{5 / 2}$ of $\mathrm{Ce}^{3+}$ ions is observed at 885.4 eV (Fig. 3(d)). Thereby, the XPS results confirm the existence of $\mathrm{Ca}, \mathrm{Al}, \mathrm{Si}, \mathrm{O}, \mathrm{Ag}$ and $\mathrm{Cl}$ elements which are the constitutional elements in the composite of $\mathrm{Ca}_{2} \mathrm{Al}_{2} \mathrm{SiO}_{7}: \mathrm{Ce}^{3+}$ and $\mathrm{Ag} / \mathrm{AgCl}$.

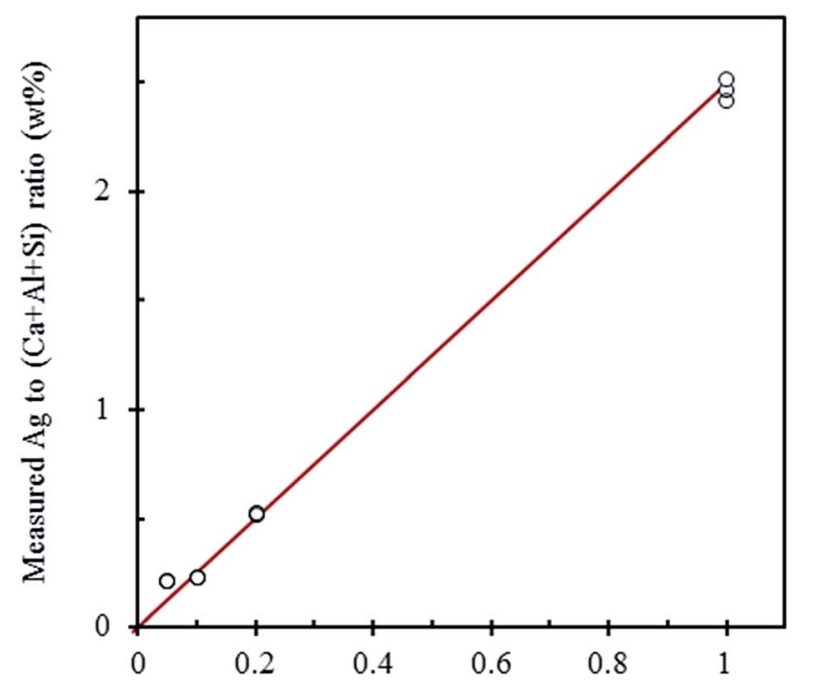

Added stoichiometry ratio of $\mathrm{Ag} / \mathrm{AgCl}$ to gehlenite (wt\%)

Fig. 2 Ag weight ratio in composites measured by XRF method plotted against the added stoichiometry. 

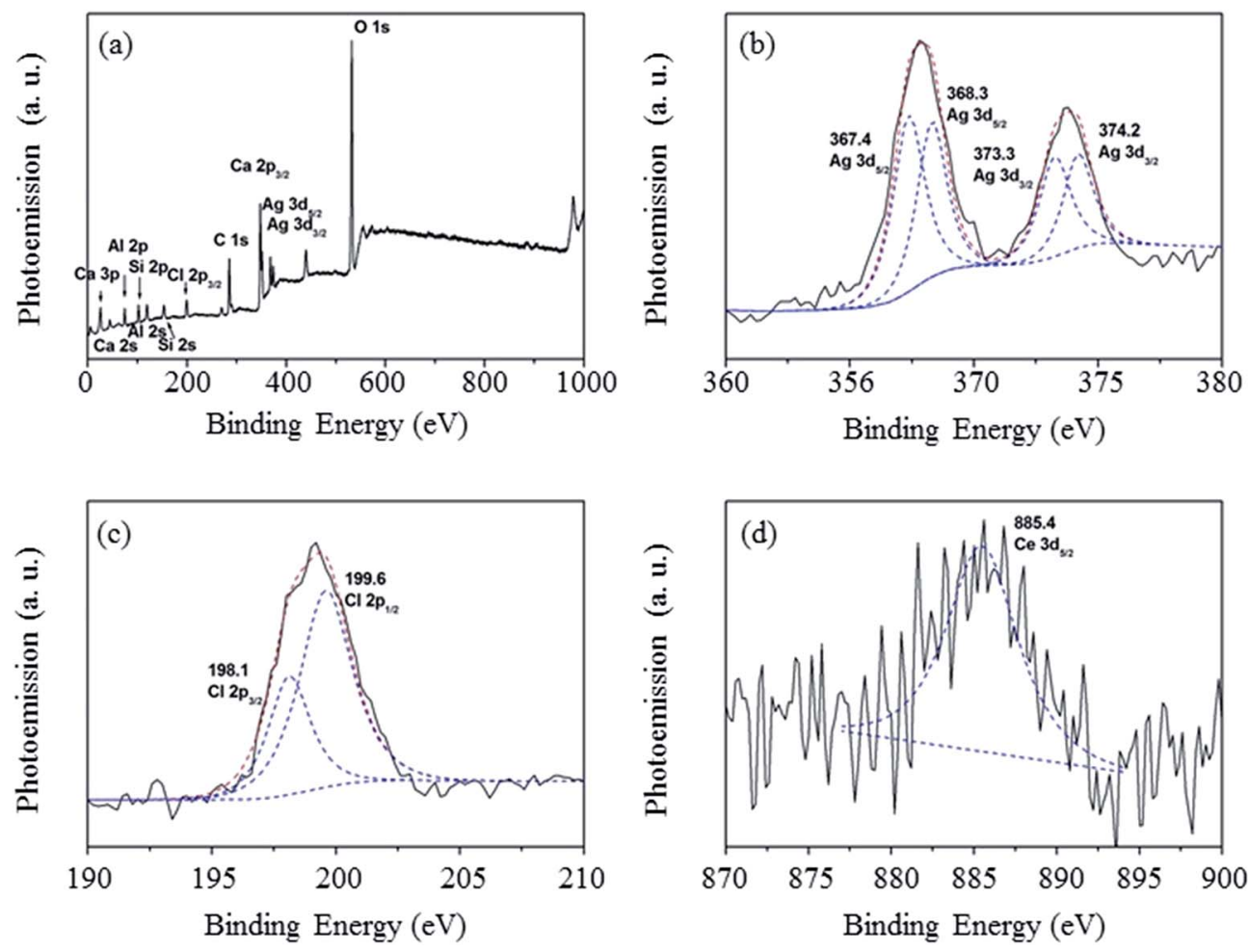

Fig. 3 The survey scan (a), the Ag 3d (b), the $\mathrm{Cl} 2 p(c)$, and the Ce $3 d$ (d) XPS results for the C10A1 sample.

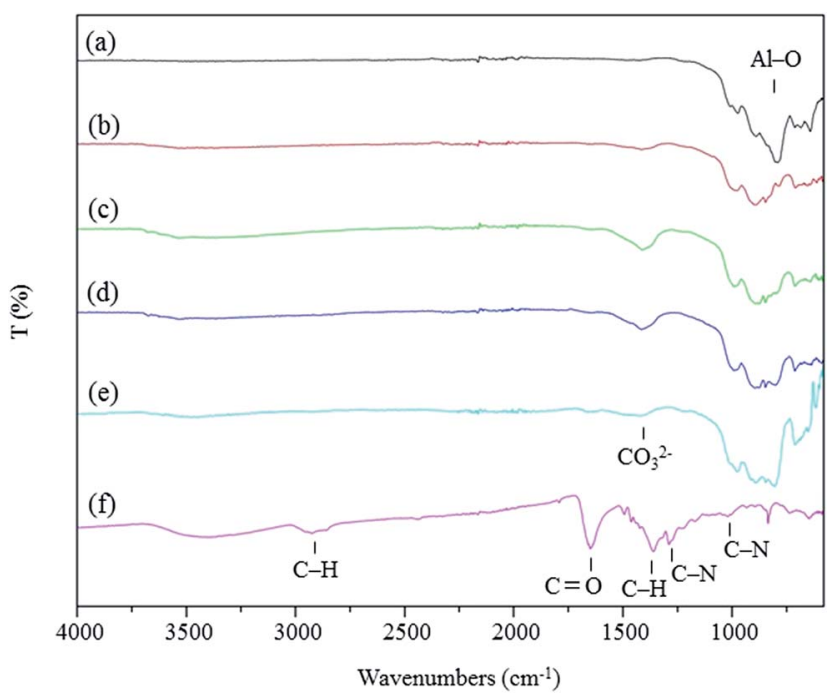

Fig. 4 FTIR spectra of the $\mathrm{Ca}_{2} \mathrm{Al}_{2} \mathrm{SiO}_{7}: \mathrm{Ce}^{3+}-\mathrm{Ag} / \mathrm{AgCl}$ composites in comparison with the pure gehlenite and the pure $\mathrm{Ag} / \mathrm{AgCl}$. (a) $\mathrm{G}$, (b) G20A1, (c) G10A1, (d) G5A1, (e) G1A1, (f) A.

Fig. 4 shows the FT-IR spectra of the G, the A, and the composite samples. For the G sample (Fig. 4(a)), peaks at $900-1000 \mathrm{~cm}^{-1}$ is attributed to the stretching mode of $\mathrm{Si}-\mathrm{O}-\mathrm{Al}$ structure in $\mathrm{Ca}_{2} \mathrm{Al}_{2} \mathrm{SiO}_{7}$ phase, and the one at $798 \mathrm{~cm}^{-1}$ is assigned to the $\mathrm{Al}-\mathrm{O}$ stretching mode in tetrahedral coordination. ${ }^{38}$ For the A sample (Fig. 4(f)), the strong absorption peaks at 1363 and $2927 \mathrm{~cm}^{-1}$, the peaks at 1281 and $1014 \mathrm{~cm}^{-1}$, and that at $1640 \mathrm{~cm}^{-1}$ are assigned to the rocking and stretching modes of the $\mathrm{C}-\mathrm{H}$, the $\mathrm{C}-\mathrm{N}$, and the $\mathrm{C}=\mathrm{O}$ groups, respectively. Such absorptions come from the PVP polymer stabilizer of $\mathrm{Ag} /$ $\mathrm{AgCl}$ particles. For the composite samples, except for the peaks due to the $\mathrm{Ca}_{2} \mathrm{Al}_{2} \mathrm{SiO}_{7}$ phase, it can be observed that the $\mathrm{Al}-\mathrm{O}$ peak is weakened, and a peak at $1430 \mathrm{~cm}^{-1}$, which can be assigned to carbonate species, appears. Thus, FT-IR result gives a same result as that by XRD, indicating that impurity decomposition and partial structural change of the LLP substrate occur during the preparation process of the composite samples. Furthermore, the relative intensity of the Al-O peak decreases with the increase of the LLP content in the composite, suggesting that it is likely that the crystal phase of the LLP can be stabilized by the loading or surrounding of the $\mathrm{Ag} / \mathrm{AgCl}$ particles in particular in samples with a greater $A$ to $G$ amount ratio.

Fig. 5 shows the SEM and TEM images of the G10A1 sample. From the SEM picture, a $\mathrm{Ca}_{2} \mathrm{Al}_{2} \mathrm{SiO}_{7}: \mathrm{Ce}^{3+}$ LLP particle $(\sim 15 \mu \mathrm{m}$ in size) was coated or loaded with a large quantity of small $\mathrm{Ag} / \mathrm{AgCl}$ particles. The TEM image clearly shows the dispersion of silver-related nanoparticles on the surface of the phosphor G, whose size $(\sim 10 \mathrm{~nm})$ are smaller in comparison with those reported previously. ${ }^{19,36}$ The EDX result confirms the signals from both $\mathrm{Ag}$ and $\mathrm{Cl}$, indicating that the nanoparticles are the $\mathrm{Ag} / \mathrm{AgCl}$ species (refer to Fig. $\mathrm{S} 4 \dagger$ also in ESI). The smaller size of $\mathrm{Ag} / \mathrm{AgCl}$ in our materials may be attributed to the polar solvent (water) condition which possibly confines the growth of the $\mathrm{Ag} / \mathrm{AgCl}$ nanoparticles by influencing the reduction rate of $\mathrm{Ag}^{+}{ }^{19}$ The smaller $\mathrm{Ag} / \mathrm{AgCl}$ particles are better to be dispersed in water and thus more easily decorated on the surface of LLPs. The close contact of the $\mathrm{Ca}_{2} \mathrm{Al}_{2} \mathrm{SiO}_{7}: \mathrm{Ce}^{3+}$ surface with the $\mathrm{Ag} / \mathrm{AgCl}$ 

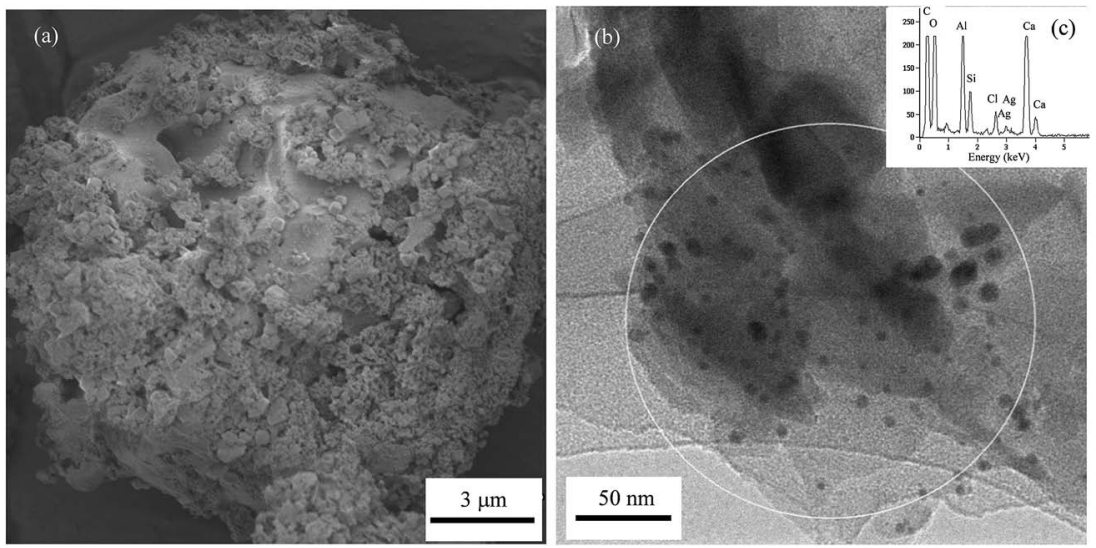

Fig. 5 (a) FE-SEM and (b) TEM images, and (c) EDX spectrum of G10A1. The EDS area is indicated by the circle in (b).

nanoparticles confirmed by the microscopic images is geometrically advantage to the absorption of not only external light but also photoemission from LLP by the photoactive Ag/ $\mathrm{AgCl}$.

\section{Photoabsorption and photoemission properties}

Fig. 6 shows the DRS spectra of $\mathrm{G}$ and G10A1 in comparison with the UV-vis spectrum of $\mathrm{Ag} / \mathrm{AgCl}$ solution dispersion. An absorption band at $350 \mathrm{~nm}$ is observed in the spectrum of the $\mathrm{G}$ sample (Fig. 6(a)). According to the excitation spectra (to be shown in Fig. 7), this absorption can be ascribed to the $4 \mathrm{f}^{1} \rightarrow$ $4 \mathrm{f}^{0} 5 \mathrm{~d}^{1}$ transition of the $\mathrm{Ce}^{3+}$ ions. ${ }^{39}$ The $\mathrm{Ag} / \mathrm{AgCl}$ colloidal solution shows a broad absorption in the visible range, centered at $\sim 420 \mathrm{~nm}$ (Fig. 6(c)). As the band gap of $\mathrm{AgCl}$ is around $3.0 \mathrm{eV}$, corresponding to a band edge of $\sim 420 \mathrm{~nm},{ }^{17}$ the enhanced visible absorption is attributed to the SPR effect of the metallic $\mathrm{Ag}$ component in the particles. ${ }^{\mathbf{1 8 , 1 9}}$ The existence of the metallic $\mathrm{Ag}$ is confirmed by the XPS results, which suggests that the $\mathrm{Ag}^{+}$ ions can be reduced to $\mathrm{Ag}^{0}$ during the synthesis process. The spectrum of G10A1 (Fig. 6(b)) exhibits both properties of G and $\mathrm{Ag} / \mathrm{AgCl}$, in which the absorption in visible wavelength range

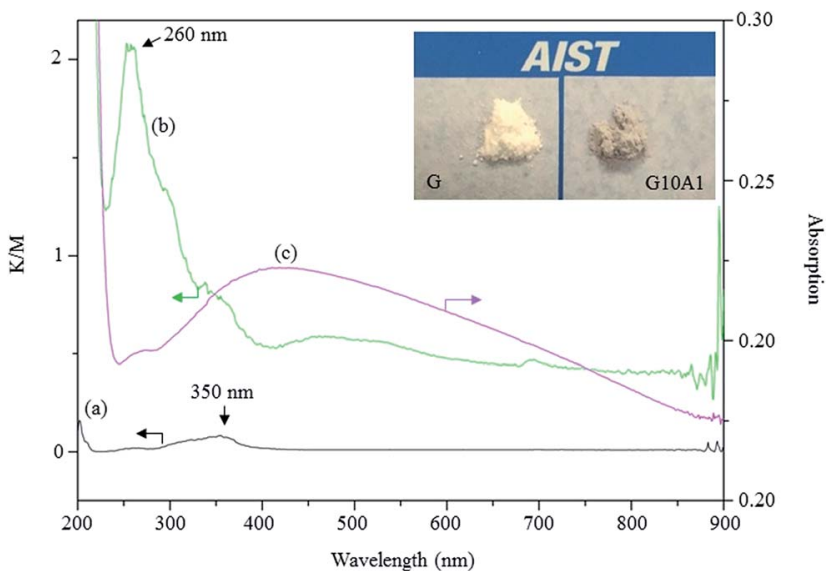

Fig. 6 DRS spectra of G10A1 (a) and G (b), and UV-vis absorption spectrum of $\mathrm{Ag} / \mathrm{AgCl}$ solution dispersion (c). from 420 to $800 \mathrm{~nm}$ is owing to the SPR absorption of $\mathrm{Ag}^{0}$ and that below $420 \mathrm{~nm}$ is mainly contributed by both the $\mathrm{AgCl}$ nanocrystal and the LLP support. ${ }^{37}$ Thus, the broad absorption band of $\mathrm{Ag} / \mathrm{AgCl}$ matches very well the emission of $\mathrm{Ca}_{2} \mathrm{Al}_{2}$ $\mathrm{SiO}_{7}: \mathrm{Ce}^{3+}$. The UV-vis spectra indicate a good composing structure, which is favorable to pick up the photoemission from $\mathrm{Ca}_{2} \mathrm{Al}_{2} \mathrm{SiO}_{7}: \mathrm{Ce}^{3+}$ and then to activate the photocatalytic reaction on $\mathrm{Ag} / \mathrm{AgCl}$.

The luminescent properties of the pure $\mathrm{G}$ and the composite samples are compared in Fig. 7. All the samples can be effectively excited by an UV light. As shown in Fig. 7(a) and (b), a broad emission and excitation band pairs, centered at $410 \mathrm{~nm}$ and at $350 \mathrm{~nm}$, respectively, are observed. The broad emission is induced by the $4 \mathrm{f}^{0} 5 \mathrm{~d}^{1} \rightarrow 4 \mathrm{f}^{1}$ transition of the $\mathrm{Ce}^{3+}$ ions as reported previously. ${ }^{40-42}$ The G sample shows the strongest emission intensity. After immersing in water for 4 hours, both peaks of excitation and emission become narrower with the intensities reduced by $\sim 30 \%$, due to the slight structural change of $\mathrm{Ca}_{2} \mathrm{Al}_{2} \mathrm{SiO}_{7}$ in water (refer to ESI and Fig. $\mathrm{S} 1$ and $\mathrm{S} 2 \dagger$ ). After the decoration of $\mathrm{Ag} / \mathrm{AgCl}$ nanoparticles, the emission intensity is further reduced and decreases dramatically with the increase of the decoration amount. This reduction is owing to the luminescence quenching and also, partially, the internal filtering effect by the decorated $\mathrm{Ag} / \mathrm{AgCl}$ particles, which increases with the increment of $\mathrm{Ag} / \mathrm{AgCl}$ content in the composite. The quantum yield (Fig. 7(c)) of the emission from the G sample is $\sim 38 \%$ under a $350 \mathrm{~nm}$ excitation, and it decreases to $\sim 32 \%$ after immersing in water for 4 hours and further to $\sim 9 \%$ after decoration of $\mathrm{Ag} / \mathrm{AgCl}$ in G10A1. Thus, more than $\sim 2 / 3$ of the photoemission is absorbed or blocked by the $\mathrm{Ag} / \mathrm{AgCl}$ particles in the composite.

The afterglow spectra (Fig. 7(d)) measured after switching off the light source for 10 seconds show emission peaks with similar shapes to those under excitation and still having strong intensities, indicating the existence of the long-lasting luminescence. Fig. 7(e) shows the decay curves of the luminescence up to 5 minute after switching-off the light source for all the samples. We found that all the decay curves can be fitted by the 

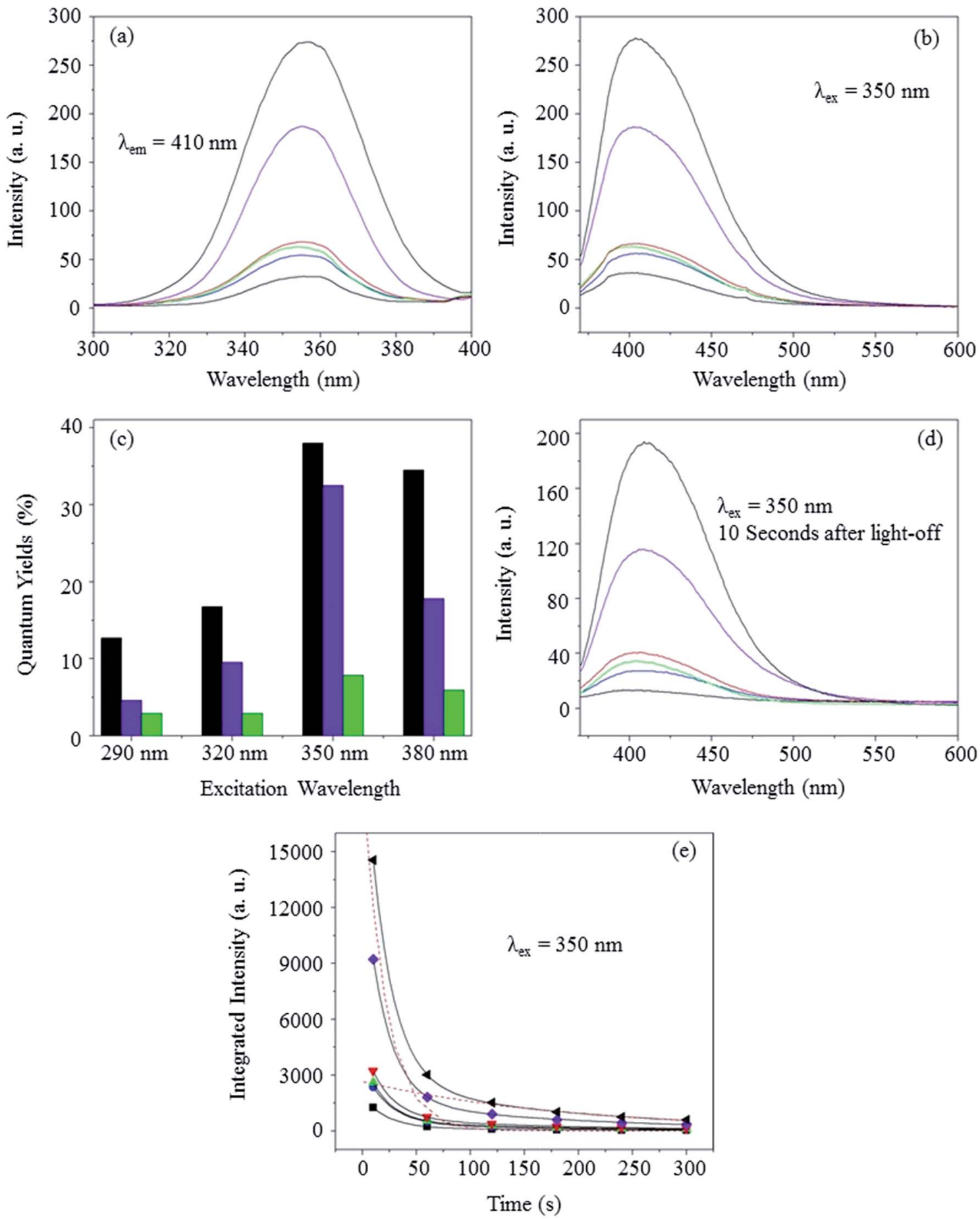

Fig. 7 (a) Excitation and (b) emission spectra with an emission of $410 \mathrm{~nm}$ and an excitation of $350 \mathrm{~nm}$, respectively, (c) comparison of quantum yields of G (black), G immersed in water for $4 \mathrm{~h}$ (blue), and G10A1 (green) at different excitation wavelengths, (d) afterglow spectra measured after switching off the excitation for 10 seconds, and (e) afterglow decay curves based on the peak $(410 \mathrm{~nm})$ intensity in (b) in which the broken curves depict the two components of the double-exponentially fitted results for the $G$ sample. Curves from top to bottom in (a), (b), (d), and (e) are $G$, $G$ immersed in water for 4 h, G20A1, G10A1, G5A1 and G1A1, respectively.

following double exponential equation containing both rapid and slow decaying components: ${ }^{41}$

$$
I=I_{1} \exp \left(-\frac{t}{\tau_{1}}\right)+I_{2} \exp \left(-\frac{t}{\tau_{2}}\right)
$$

where $I, I_{1}$, and $I_{2}$ represent the total, rapid and slow component phosphorescent intensities, respectively, and $t, \tau_{1}$, and $\tau_{2}$ are the decay time, the decay constants of rapid and slow components, respectively. As shown in Table 1, the increase of the decoration amount of $\mathrm{Ag} / \mathrm{AgCl}$ reduces not only the luminescent intensity 
Table 1 Fitted parameters of the decay curves

\begin{tabular}{lllll}
\hline Samples & $I_{1}$ (a.u.) & $\tau_{1}(\mathrm{~s})$ & $I_{2}$ (a.u.) & $\tau_{2}(\mathrm{~s})$ \\
\hline G & 19529 & 20 & 2662 & 192 \\
G 4 h in water & 12620 & 20 & 1617 & 189 \\
G20A1 & 4088 & 21 & 713 & 172 \\
G10A1 & 3446 & 20 & 524 & 162 \\
G5A1 & 3074 & 22 & 390 & 163 \\
G1A1 & 1699 & 21 & 183 & 148
\end{tabular}

but also the afterglow life time of the slow component, suggesting that catalyst $(\mathrm{Ag} / \mathrm{AgCl})$-support (LLP) interaction may happen and somehow modify the energy levels of the slower long-lasting sites on the original LLP.

\section{Photocatalytic properties}

MO degradation test was carried out to demonstrate the continuous photocatalysis by simulated sunlight illumination and subsequently by switching off the light source. In order to particularly evaluate the contribution of LLP to photocatalytic performance after light-off, the amount of composite in these tests was determined in such a wise that their content of $\mathrm{Ag} / \mathrm{AgCl}$ is maintained to be $5 \mathrm{mg}$, and $5 \mathrm{mg} \mathrm{Ag} / \mathrm{AgCl}$ (A sample) and $50 \mathrm{mg} \mathrm{Ca}_{2} \mathrm{Al}_{2} \mathrm{SiO}_{7}: \mathrm{Ce}^{3+}$ (G sample) were employed as the control samples. As shown in Fig. 8(a), a pre-illumination step D (the first 30 minutes in dark) showed that the $\mathrm{G}$ sample can adsorb a little amount of MO whereas the G10A1 and A samples have no adsorption affinity toward MO. After irradiated by a simulated solar for 5 minutes (step I), the concentrations of MO were decreased dramatically by G10A1 and A, but kept unchanged by $\mathrm{G}$. The result reveals that the $\mathrm{Ag} / \mathrm{AgCl}$ rather than the $\mathrm{Ca}_{2} \mathrm{Al}_{2} \mathrm{SiO}_{7}: \mathrm{Ce}^{3+}$ can decompose the MO efficiently. The little decrease in photocatalytic effect of G10A1 as compared to the pure A sample is attributed to the light filtering or scattering effect due to the existence of the $\mathrm{Ca}_{2} \mathrm{Al}_{2} \mathrm{SiO}_{7}: \mathrm{Ce}^{3+}$. Fig. 8(b) shows the time course of the long-lasting step (step A) at which the MO concentration (the ordinate) was reduced by the starting concentration of $\mathrm{MO}$ at step $\mathrm{A}\left(C_{\mathrm{AO}}\right)$. It is evident that the existence of LLP serves as an excitation source for the $\mathrm{Ag} / \mathrm{AgCl}$ so that the dye degradation process is continuing after switching off the external light source. Around 15\% of the retained MO can be further decomposed by the effect after the removal of excitation for 20 minutes. Fig. 8(c) compares the degradation ratio of MO among various samples. All the composite samples exhibit a similar degradability (79-80\%) toward MO under solar irradiation but only those with sufficient LLP amount show a larger long-lasting degradation. The long lasting degradation amount (11-15\%) of the composites is comparable with or slightly higher than the previous reports where $\mathrm{Sr}_{4} \mathrm{Al}_{14} \mathrm{O}_{25}: \mathrm{Eu}$, $\mathrm{Nd}$ or $\mathrm{BaZrO}_{3}: \mathrm{Mg}$ was applied as LLP and $\mathrm{TiO}_{2}$ as photocatalyst. $^{20,27}$ On the other hand, only a little amount of MO can be degraded by G10T1 under solar degradation and the MO degradation in step $\mathrm{A}$ is negligible. Hence, the composite structure, the amount of LLP, the matching of light source spectrum and the emission wavelength of LLP with photoactive
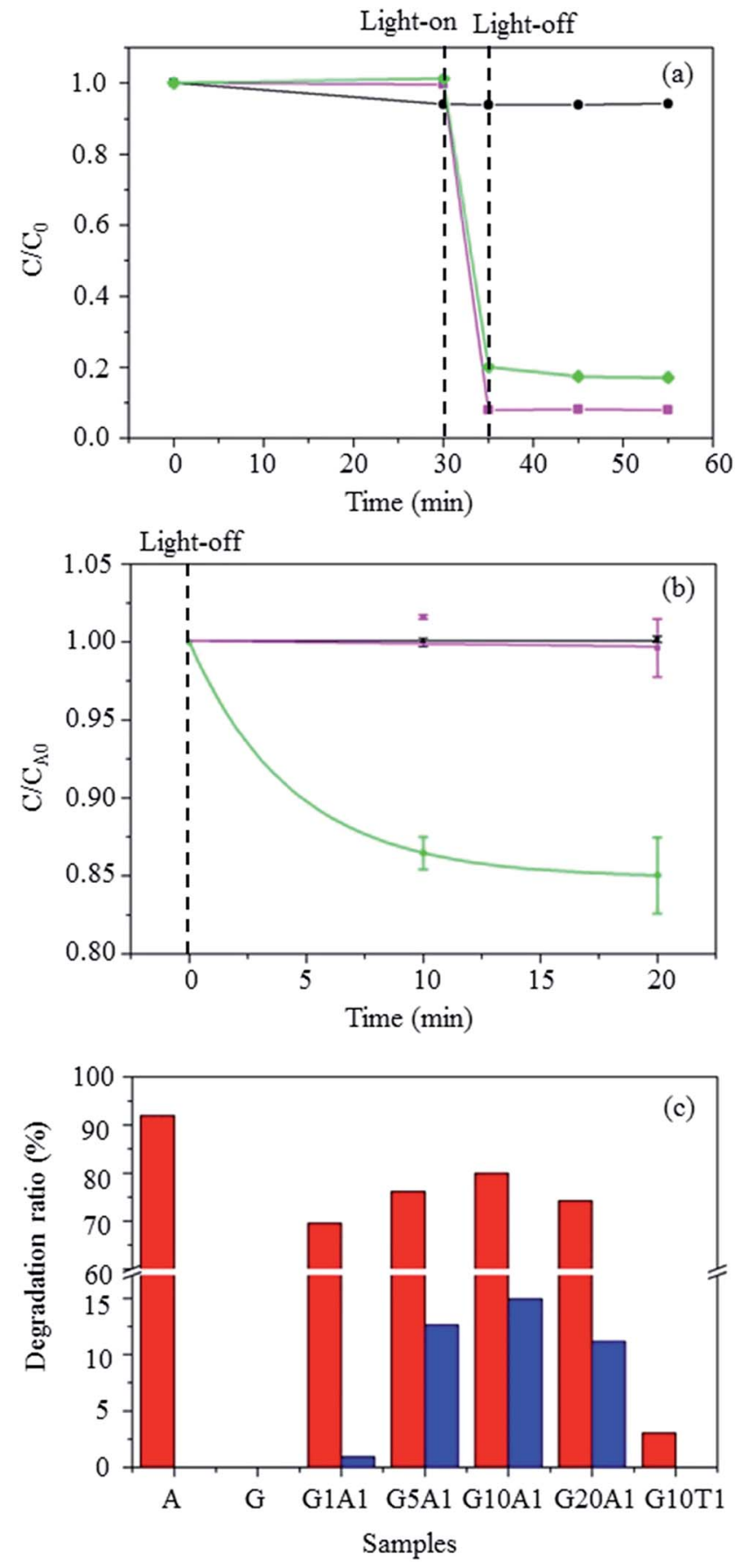

Fig. 8 Time-dependent $M O$ degradation process of samples $G(\bullet)$, G10A1 ( $\bullet$ ), and A ( $\square$ ), (b) the expansion of the long lasting (the afterlight-off) step $A$ in (a) with the ordinate expressed by $C / C_{A 0}$, and (c) comparison of the degradation ratio of $\mathrm{MO}$ under solar irradiation (red, left) and the long lasting step $A$ (blue, right) in relative to $C_{0}$ (red) and $C_{\mathrm{AO}}$ (blue), respectively.

species are the important factors to realize a significant longlasting photodegradation effect.

Fig. 9 depicts the proposed mechanism for the long-lasting photocatalysis. The generation of afterglow has been studied systematically. ${ }^{33-35}$ It is well agreed that oxygen vacancies (two positive charges equivalent) can be induced during the 

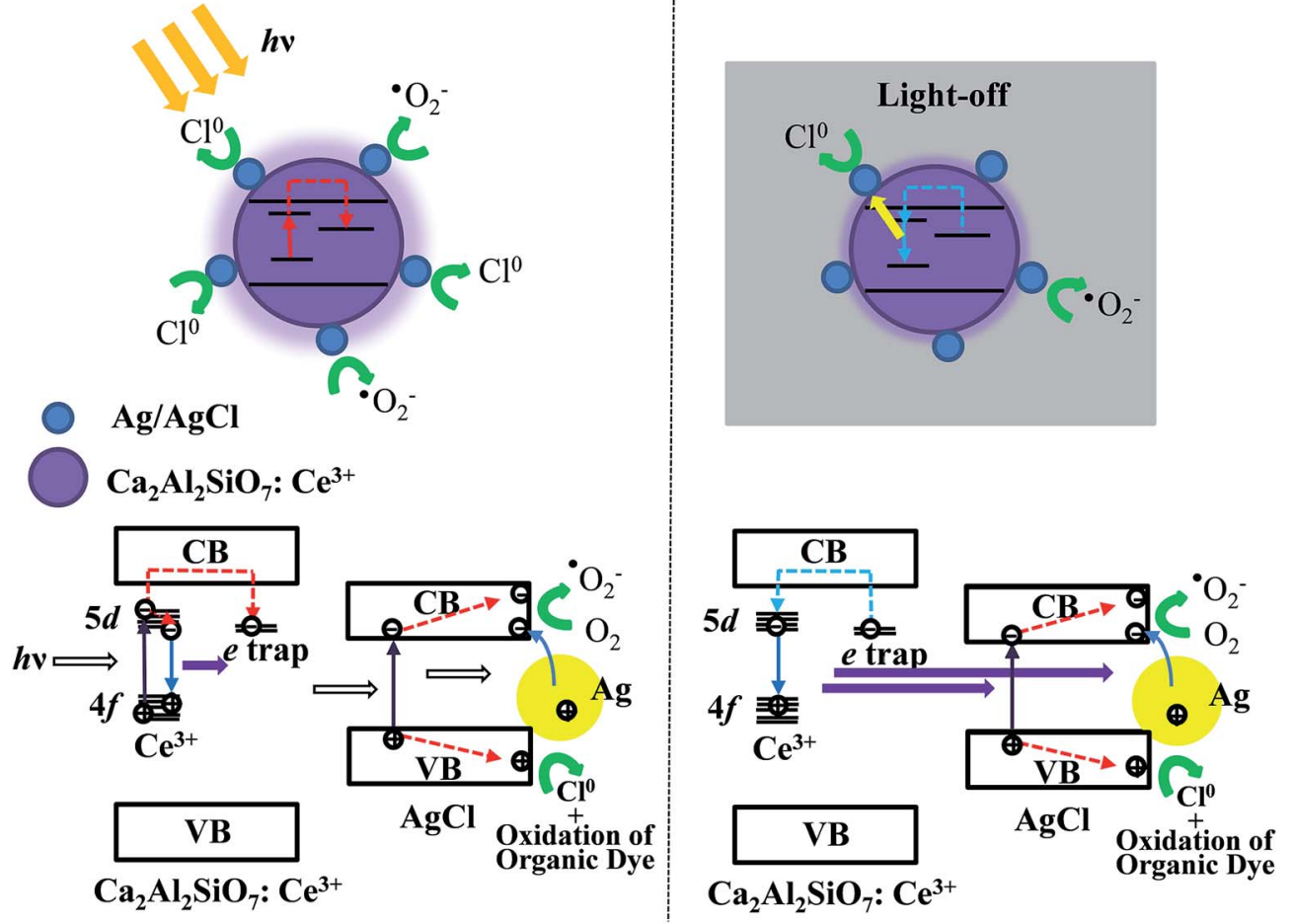

Fig. 9 Schematic description on the proposed mechanism of the phosphor supporting photocatalysis.

synthesis of the matrix phosphor in reducing atmosphere, whose energy level is close to the conduction band. Then oxygen vacancies can act as electron traps to delay the electron-hole recombination in luminescent center. ${ }^{33-35,42}$ The lasting photocatalysis upon exciting and extinguishing of the excitation can thus be considered as follows: (1) when $\mathrm{Ca}_{2} \mathrm{Al}_{2} \mathrm{SiO}_{7}: \mathrm{Ce}^{3+}$ $\mathrm{Ag} / \mathrm{AgCl}$ is irradiated by solar, the photo-induced reaction of $\mathrm{MO}$ occurs on the surface of $\mathrm{Ag} / \mathrm{AgCl}$, and, simultaneously, the $4 \mathrm{f}^{1}$ $\rightarrow 4 f^{0} 5 d^{1}$ transition of $\mathrm{Ce}^{3+}$ in LLP occurs. Since the $5 \mathrm{~d}$ state of $\mathrm{Ce}^{3+}$ is very close to the conduction band, parts of the electrons in $5 \mathrm{~d}$ state of $\mathrm{Ce}^{3+}$ jump to $\mathrm{CB}$, which become free electrons and are finally captured by oxygen vacancies whose energy barrier prevents them from rapid recombination. (2) After the elimination of irradiation, while the photoreaction induced by external light source is deactivated, the trapped electrons on LLP can be thermally liberated and return to $\mathrm{Ce}^{3+}$. The photoemission due to their recombination with holes is then absorbed by $\mathrm{Ag} / \mathrm{AgCl}$ species by which the long-lasting photodegradation is activated again. Regarding the photocatalytic activity, it is known that the metallic Ag generates hot electrons by visible light irradiation due to the SPR effect, which can be injected into the $\mathrm{CB}$ of $\mathrm{AgCl}$. While the photo-induced electrons in $\mathrm{CB}$ can react with oxygen to form ${ }^{\circ} \mathrm{O}_{2}{ }^{-}$species which efficiently decompose organic dye, it was proposed that the photo-induced holes left in VB can oxidize organic dye directly by involving the reaction of $\mathrm{Cl}^{-}$species (the cycle of $\mathrm{Cl}^{-}$ $\left.\rightarrow \mathrm{Cl}^{0} \rightarrow \mathrm{Cl}^{-}\right){ }^{36,43,44}$ The repeating photocatalytic experiment in the current work (Fig. S5 and S6 in ESI $\dagger$ ) indicates that a part of $\mathrm{Ag} / \mathrm{AgCl}$ loaded on LLPs may not be stable and the permanent reduction of $\mathrm{Cl}^{-}$(or the formation of $\mathrm{Ag}^{0}$ species) under photo- irradiation can increase the irradiation filtering effect on LLPs, resulting in the retarded photocatalytic reaction in the longlasting part after second repeating run.

\section{Conclusions}

The $\mathrm{Ca}_{2} \mathrm{Al}_{2} \mathrm{SiO}_{7}: \mathrm{Ce}^{3+}-\mathrm{Ag} / \mathrm{AgCl}$ composites are successfully fabricated by decorating $\mathrm{Ag} / \mathrm{Ag} \mathrm{Cl}$ nanoparticles on the surface of $\mathrm{Ca}_{2} \mathrm{Al}_{2} \mathrm{SiO}_{7}: \mathrm{Ce}^{3+}$. The composites can efficiently degrade organic dyes under solar irradiation. Benefit from the longlasting luminescence of $\mathrm{Ca}_{2} \mathrm{Al}_{2} \mathrm{SiO}_{7}: \mathrm{Ce}^{3+}$, the $\mathrm{Ag} / \mathrm{AgCl}$ can be excited by the afterglow after the elimination of irradiation. The dye-degradation process can be continued and about $15 \%$ of the retained dye can be decomposed without any external excitation. The Si-based $\mathrm{Ca}_{2} \mathrm{Al}_{2} \mathrm{SiO}_{7}: \mathrm{Ce}^{3+}-\mathrm{Ag} / \mathrm{Ag} \mathrm{Cl}$ is relatively stable in water as compared to the commercial Al-based materials with high brightness. These phosphors supporting photocatalysts can be expected to be the potential materials for outdoor water treatment by further elevating the afterglow degradability through the improvement of the afterglow intensity, the water resistance of phosphors, and the stability of photocatalysts, and by idealizing the composite structure.

\section{Acknowledgements}

This work is financially supported by the Japan Society for the Promotion of Science. Dr K. Kawaguchi of IBEC, AIST is grateful for the assistance of XPS measurement. 


\section{References}

1 A. Fujishima and K. Honda, Nature, 1972, 238, 27-38.

2 J. Schneider, M. Matsuoka, M. Takeuchi, J. Zhang, Y. Horiuchi, M. Anpo and D. W. Bahnemann, Chem. Rev., 2014, 114, 9919-9986.

3 M. Pelaez, N. T. Nolan, S. C. Pillai, M. K. Seery, P. Falaras, A. G. Contos, P. S. M. Dunlop, J. W. J. Hamilton, J. A. Byrne, K. O'Shea, M. H. Entezari and D. D. Dionysiou, Appl. Catal., B, 2012, 125, 331-349.

4 R. M. Mohamed, D. L. Mckinney and W. M. Sigmund, Mater. Sci. Eng., R, 2012, 73, 1-13.

5 J. Tian, Z. Zhao, A. Kumar, R. I. Boughton and H. Liu, Chem. Soc. Rev., 2014, 43, 6920-6937.

6 S. Banerjee, S. C. Pillai, P. Falaras, K. E. O'Shea, J. A. Byrne and D. D. Dionysiou, J. Phys. Chem. Lett., 2014, 5, 2543-2554.

7 A. L. Linsebigler, G. Lu and J. T. Yates Jr, Chem. Rev., 1995, 95, 735-758.

8 H. Dong, G. Zeng, L. Tang, C. Fan, C. Zhang, X. He and Y. He, Water Res., 2015, 79, 128-146.

9 J. Chen, F. Qiu, W. Xu, S. Cao and H. Zhu, Appl. Catal., A, 2015, 495, 131-140.

10 S. J. A. Moniz, S. A. Shevlin, D. J. Martin, Z.-X. Gao and J. Tang, Energy Environ. Sci., 2015, 8, 731-759.

11 H. Tong, S. Ouyang, Y. Bi, N. Umezawa, M. Oshikiri and J. Ye, Adv. Mater., 2012, 24, 229-251.

12 J. L. Yang, S. J. An, W. I. Park, G.-C. Yi and W. Choi, Adv. Mater., 2014, 16, 1661-1664.

13 S. K. Kasnal, M. Singh and D. Sud, J. Hazard. Mater., 2007, 141, 581-590.

14 C. Lin, C. Wu and Z. Onn, J. Hazard. Mater., 2008, 154, 10331039.

15 Z. Jiao, T. Chen, J. Xiong, T. Wang, G. Lu, J. Ye and Y. Bi, Sci. Rep., 2013, 3, 2720.

16 P. Wang, B. Huang, Y. Dai and M.-H. Whangbo, Phys. Chem. Chem. Phys., 2012, 14, 9813-9825.

17 X. Zhang, Y. L. Chen, R.-S. Liu and D. P. Tsai, Rep. Prog. Phys., 2013, 76, 046401.

18 P. Wang, B. Huang, X. Qin, X. Zhang, Y. Dai, J. Wei and M.-H. Whangbo, Angew. Chem., Int. Ed., 2008, 47, 7931-7933.

19 C. An, S. Peng and Y. Sun, Adv. Mater., 2010, 22, 2570-2574.

20 J. Zhang, F. Pan, W. Hao, Q. Ge and T. Wang, Appl. Phys. Lett., 2004, 85, 5778-5780.

21 H. Li, S. Yin, Y. Wang, T. Sekino, S. W. Lee and T. Sato, J. Mater. Chem. A, 2013, 1, 1123-1126.

22 H. Li, S. Yin and T. Sato, Appl. Catal., B, 2011, 106, 586-591.
23 H. Li, S. Yin, Y. Wang and T. Sato, Environ. Sci. Technol., 2012, 46, 7741-7745.

$24 \mathrm{H}$. Li, S. Yin and T. Sato, Nanoscale Res. Lett., 2011, 6, 5-8.

25 H. Li, S. Yin, Y. Wang and T. Sato, J. Mol. Catal. A: Chem., 2012, 363-364, 129-133.

26 H. Li, S. Yin, Y. Wang and T. Sato, Res. Chem. Intermed., 2013, 39, 1501-1507.

27 X. Ma, J. Zhang, H. Li, B. Duan, L. Guo, M. Que and Y. Wang, J. Alloys Compd., 2013, 580, 564-569.

28 S. Li, W. Wang, Y. Chen, L. Zhang, J. Guo and M. Gong, Catal. Commun., 2009, 10, 1048-1051.

29 H. Yin, X. Chen, R. Hou, H. Zhu, S. Li, Y. Hou and H. Li, ACS Appl. Mater. Interfaces, 2015, 7, 20076-20082.

30 Y. Meng, Y. Shen, L. Hou, G. Zuo, X. Wei, X. Wang and F. Li, J. Alloys Compd., 2016, 655, 1-5.

31 F. Locardi, E. Sanguineti, M. Fasoli, M. Martini, G. A. Costa, M. Ferretti and V. Caratto, Catal. Commun., 2016, 74, 24-27. 32 B. Qu, B. Zhang, L. Wang, R. Zhou and X. C. Zeng, Chem. Mater., 2015, 27, 2195-2202.

33 T. Aitasalo, J. Hölsä, H. Jungner, M. Lastusaari and J. Niittykoski, J. Phys. Chem. B, 2006, 110, 4589-4598.

34 F. Clabau, X. Rocquefelte, S. Jobic, P. Deniard, M.-H. Whangbo, A. Garcia and T. Le Mercier, Chem. Mater., 2005, 17, 3904-3912.

35 F. Clabau, X. Rocquefelte, T. Le Mercier, P. Deniard, S. Jobic and M.-H. Whangbo, Chem. Mater., 2006, 18, 3212-3220.

36 Y. Tang, Z. Jiang, G. Xing, A. Li, P. D. Kanhere, Y. Zhang, T. C. Sum, S. Li, X. Chen, Z. Dong and Z. Chen, Adv. Funct. Mater., 2013, 23, 2932-2940.

37 B. G. Ershov, E. Janata, A. Henglein and A. Fojtik, J. Phys. Chem., 1993, 97, 4589-4594.

38 V. K. Jha, Y. Kameshima, K. Okada and K. J. D. Mackenzia, Sep. Purif. Technol., 2004, 40, 209-215.

39 M. Yamaga, Y. Ohsumi, T. Nakayama, N. Kashiwagura, N. Kodama and T. P. J. Han, J. Mater. Sci.: Mater. Electron., 2009, 20, S471-S475.

40 V. C. Teixeira, P. J. R. Montes and M. E. G. Valerio, Opt. Mater., 2015, 36, 1580-1590.

41 H. Wu, Y. Hu, G. Ju, L. Chen, X. Wang and Z. Yang, J. Lumin., 2011, 131, 2441-2445.

42 M. Yamaga, Y. Tanii, N. Kodama, T. Takahashi and M. Honda, Phys. Rev. B: Condens. Matter Mater. Phys., 2002, 65, 235108.

43 C. Han, L. Ge, C. Chen, Y. Li, Z. Zhao, X. Xiao, Z. Li and J. Zhang, J. Mater. Chem. A, 2014, 2, 12594-12600.

44 B. Cai, J. Wang, S. Gan, D. Han, T. Wu and L. Niu, J. Mater. Chem. A, 2014, 2, 5280-5286. 